\title{
Development of Single Stage Thyristor Based Grid Connected Single Phase Inverter for Renewable Energy Systems
}

\author{
Mohd Rizwan Khalid \\ Research Scholar, Electrical Engineering Dept, Zakir Husain College of Engineering and Technology, Aligarh, India
}

\begin{abstract}
Due to increase in the level of pollution and depletion of ozone layer, set-up of new fossil fuel based power generation plants are losing trend day by day and the new trend is moving towards the set-up of renewable resources based power plants. A large number of renewable energy sources based inverters have already been developed to integrate the resources into power system at distribution level. For this purpose, both single-stage and multi-stage converters are being used. Recently, thyristorbaseddc-to-ac converters are also used as low-power, grid connected inverters for solar photovoltaic (PV) applications. This paper proposes a single phase grid-tied inverter which gives lower harmonics in input line current as compared to conventional line commutated grid connected inverters. The proposed converter is analysed in continuous, just continuous and discontinuous modes. The optimum switching condition at which harmonics in the line current isminimum is obtained. The performances of conventional and proposed topology are compared through MATLAB/Simulink based models.
\end{abstract}

Keywords: Harmonic current, dc-to-ac converters, renewable energy, Total Harmonic Distortion (THD), Magnetic field intensity (H), Flux density (B).

\section{INTRODUCTION}

As per the U.S. Energy Information Administration, the global electricity consumption is going to increase from $13,934 \mathrm{TWh}$ in 2001 to $24,673 \mathrm{TWh}$ in 2025 , at an average annual rate of $2.4 \%$. The conventional methods of power generation from fossil fuels cannot meet this increased energy demand due to the depletion of fossil fuels and the global warming. This gives opportunity of integrating power from renewable energy sources to the utility grid. The centralized renewable power generation is efficacious, however enormous investments, permission of the government, land acquisition, and right of way are the issues that restrict their establishment. For these reasons, decentralized or off-grid generating systems are more attractive. In the last several years, there is substantial novelty in integrating power from renewable sources to the utility grid, giving due significance to design, control strategy, and operation of grid-connected solid state inverters [1], [2].

The requirements of low power grid connected inverters are: low cost, high efficiency and capability of withstanding variations in ac grid voltage. These requirements lead to the evolution of simpler inverter configurations having less components, and rigid modular design [1], [2]. These grid interactive inverters increase the overall efficiency of renewable energy based systems as mentioned in [3]. The efficiency of the inverter depends on the topology used, control strategy, switching loses, and other parameters. The highest efficiency reported for commercial inverter is in between $94 \%$ and $95 \%$ [3].
Injecting power from renewable energy sources to grid has some rigid requirements. One of them is improved quality of power from device, which points to power efficient, variable output voltage low harmonic distortion converters [4]. The IES has established limits to all low power single phase equipment with an active input power less than 600 $\mathrm{W}$ [5]. The standard is met by adding large passive filters, which increase size, weight and cost of the inverter.This standard is the motivation for development of control methods for improving quality of the current injected into the grid and to enhance the power factor as well.

The propagation mechanism of second harmonic current for a two-stage single phase inverter consisting of a frontend dc-dc stage and a downstream dc-ac stage is analyzed in [7], and two control methods to reduce second harmonic current have been proposed.

In [6], thyristors based simple, low cost, multilevel ac-todc converters are used as low power grid connected inverters for solar PV applications. However, the harmonics in the line current of these converters are significantly high and the total harmonic distortion (THD) varies between $18 \%$ and $23 \%$ [6]

This paper proposes a new topology for single phaseline commutated thyristor based dc-to-ac converter. With the proposed topology, the THD in line current is reduced to below 5\% in some cases. Proposed topology also have other advantages over the conventional topology like low weight, less cost and small size. 
The paper is organized as follows. Concept of positive or negative but the average value of the output conventional line commutated inverter along with voltage will be positive for RL load. However, for an different operational modes i.e. (a) Just Continious active RLE(-) load, the converter operates in fourth Conduction, (b) Continuous Conduction, and (c) quadrant of voltage-current plane and voltage become Discontinuous Conduction mode is presented in Section II. negative as shown in Fig. 2. However load current ( $i_{\mathrm{dc}}$ ) In Section III new proposed topology is discussed. Section may be discontinuous, just continuous or continuous. It IV presents a detailed comparison of both conventional depends on switching angle and impedance angle of RL and proposed topology, and finally, the conclusion is load. The equation of line current $\left(\mathrm{i}_{\mathrm{ac}}\right)$ is given in equation drawn in Section V.

1.

\section{CONVENTIONAL LINE COMMUTATED TOPOLOGY}

A full wave midpoint converter circuit with RLE load (Fig.1) works in two modes of operation, rectification mode and inversion mode.

It works in inversion mode when the switching angle of each thyristor is greater than $90^{\circ}$ and an active inductive load [RLE(-)] is used.

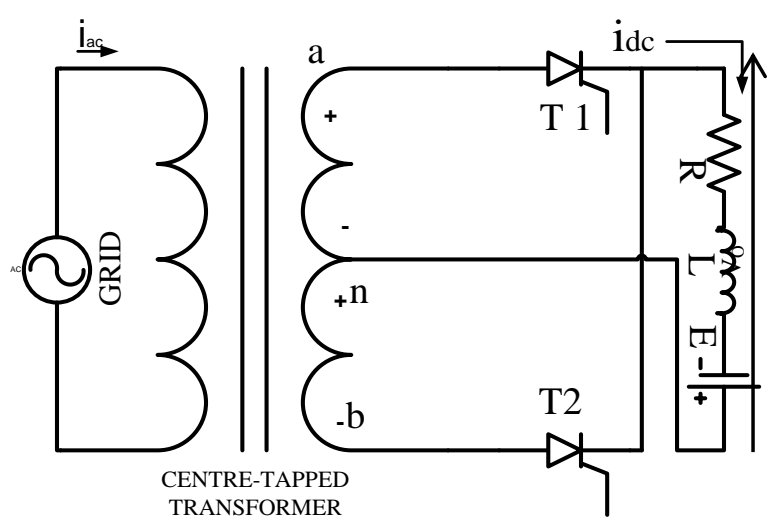

Fig.1Conventionalline commutated ac-dc converter with RLE(-) load

When, the circuit works in inversion mode, the dc source transfer power to the ac source. Ideally, there should be a lossless inductor but practical inductor is not lossless, therefore a series resistance also appears in the circuit. The $\mathrm{dc}$ side is isolated from grid via centre-tapped transformer.

A. Full wave midpoint ac-to-dc converter as a inverter The phase controlled ac- to-dc converter employing thyristorsis extensively used for changing ac input voltage to controlled dc voltage.

A thyristor is turned off as ac supply reverse biases it, provided anode current has fallen to a level below the holding current. The commutation of thyristor by supply voltage itself is called natural, or line commutation.

The phase controlled ac-to-dc converter is a two-quadrant converter (Fig. 2) in which voltage polarity can reverse but current direction cannot reverse because of the unidirectional nature of thyristors.

Since thyristor is a unidirectional device, the direction of current through it always remains same. However, due to an RL load, the instantaneous value of voltage may be

$$
\begin{aligned}
\mathrm{i}_{\mathrm{ac}}= & \frac{\sqrt{2} \cdot \mathrm{V}_{\mathrm{ac}}}{\mathrm{Z}}\left[\sin (\omega t-\varphi)-\sin (\alpha-\varphi) \cdot \exp \left(\frac{\alpha-\omega \mathrm{t}}{\tan \varphi}\right)\right] \\
& -\frac{\mathrm{E}}{\mathrm{R}}\left\{1-\exp \left(\frac{\alpha-\omega \mathrm{t}}{\tan \varphi}\right)\right\}
\end{aligned}
$$

where:

$\mathrm{Vac}=$ voltage on secondary side of transformer

$\alpha=$ Firing angle

$\phi=$ Impedance angle on DC side, and $\alpha<\omega \mathrm{t}<\beta$.

B. Analysis of conventional ac-dc converter with RLE(-) load

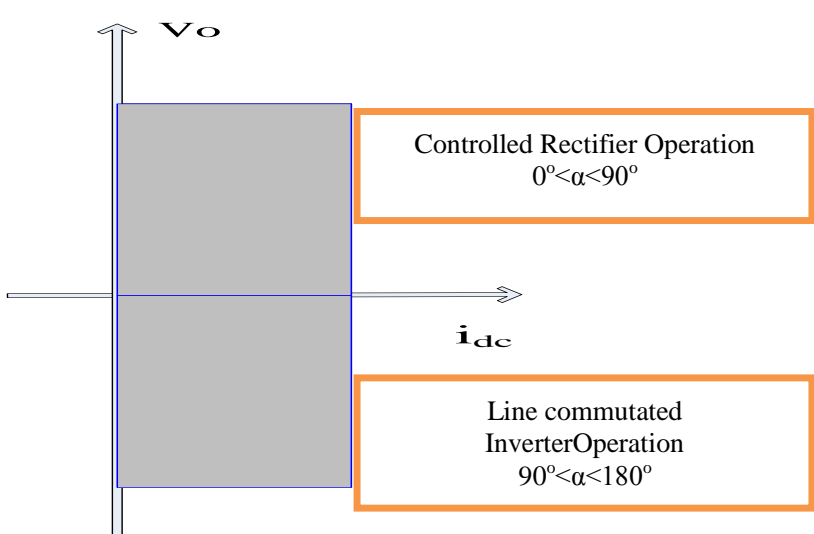

Fig. 2 Two-quadrant converter

Fig.1 shows ac-to-dc converter with active RLE(-) load which acts as a line commutated inverter for switching angle greater than $90^{\circ}$, it consists of one inductor and dc source at the load side.

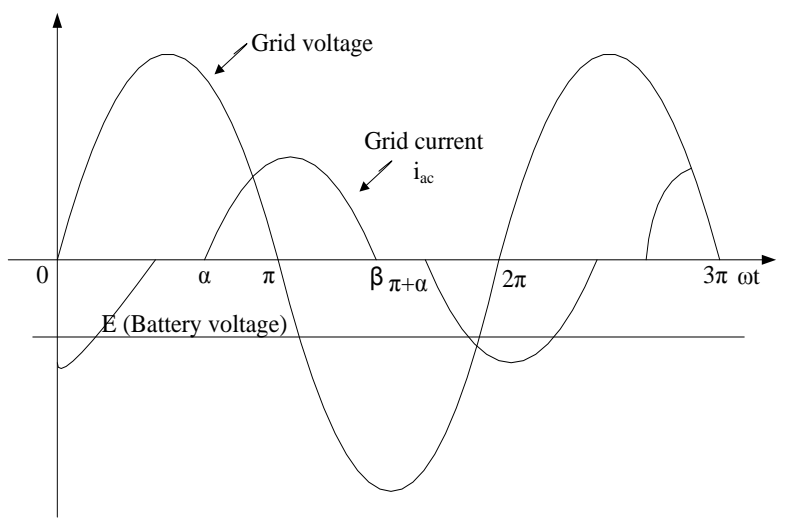

(a) Discontinious Conduction mode. 


\section{International Journal of Innovative Research in Electrical, Electronics, Instrumentation and Control Engineering}

\section{ISO 3297:2007 Certified}

Vol. 5, Issue 2, February 2017

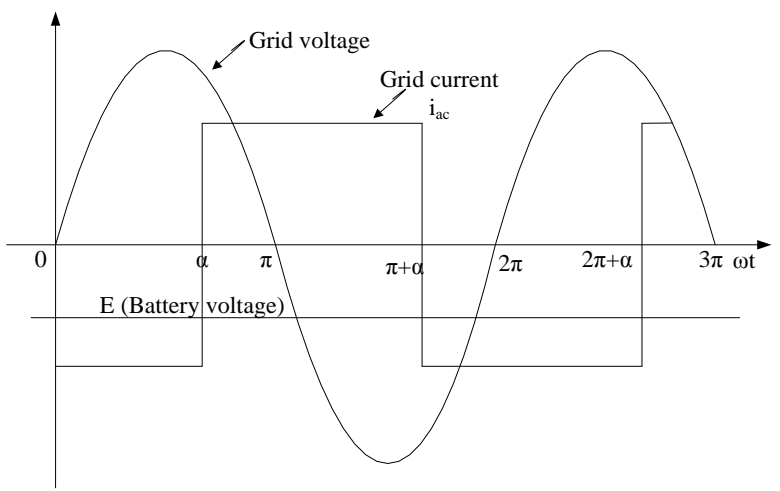

(b) Continious Conduction mode.

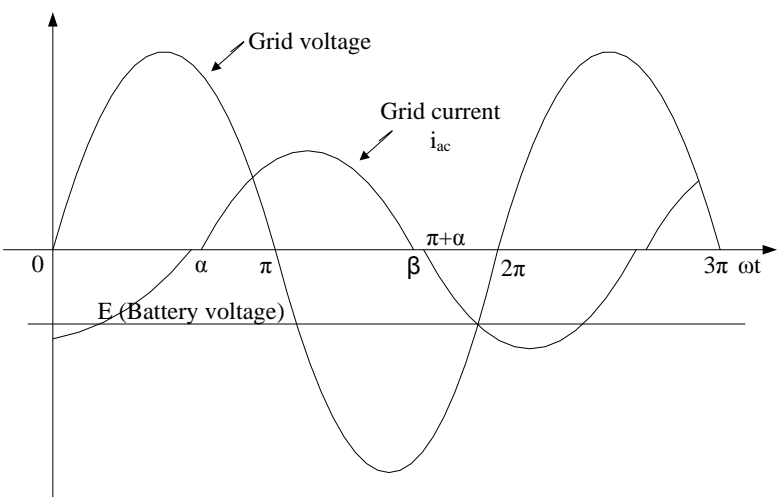

(c) Just Continious Conduction mode.

Fig. 3 Conduction modes of the line commutated ac-dc converter

Anode of both thyristors are connected to the two secondary terminals of the center-tapped transformer. Cathode of both thyristors are common and is connected to the dc load terminal while the other terminal of the dc load is connected to the centre-tapped winding of the transformer.

In the positive half cycle of grid voltage,thyristor $T_{1}$ is triggered at an angle ' $\alpha$ '. During negative half cycle thyristor $T_{2}$ is triggered at an angle' $180+\alpha$ '.

This converter acts as a line commutated inverter with discontinuous; continuous and just continuous load current as shown in Fig. 3.

In discontinuous conduction mode Fig.3(a) line current is discontinuous and THD in line current is high

In continuous conduction mode line current is continuous having square shaped waveform as shown in Fig.3(b) having $48.84 \%$ THD. Power transferred to grid is highest among all cases shown in Fig 3.

In just continuous conduction mode line current is made just continuous by firing the thyristor as soon as the other thyristor stops conduction as shown in Fig 3(c). In this case THDin line current isquite low.

\section{III.PROPOSED LINE COMMUTATED TOPOLOGY}

In proposed topology instead of one inductor at load side two separate branches are used. Where each branch consists of one inductor and one thyristor as shown in Fig.4.

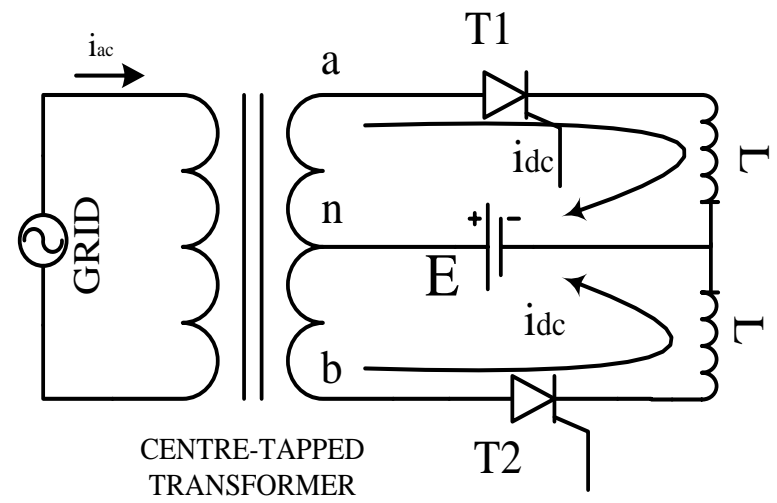

Fig.4Proposed line commutated ac-dc converter with RLE (-) load

Thyristor $\left(\mathrm{T}_{1}\right)$ with upper inductor formspositive load branch which is switched in positivehalf cycles of grid voltage. Similarly, Thyristor $\left(\mathrm{T}_{2}\right)$ with lower inductor forms a negative load branch which is switched in negativehalf cycles of gridvoltage. Dc load current $\left(\mathrm{i}_{\mathrm{dc}}\right)$ flows in upper inductor only when thyristor $\left(\mathrm{T}_{1}\right)$ is on, similarly $\left(i_{d c}\right)$ flows in lower inductor only when thyristor $\left(\mathrm{T}_{2}\right)$ is on, thus in both branches $\left(\mathrm{i}_{\mathrm{dc}}\right)$ is discontinuous and goes to zero level.

As $\left(i_{\mathrm{dc}}\right)$ goes to zero level in proposed topology, inductors on dc side do not goes in the saturation region as there is wide variation of magnetic field intensity $(\mathrm{H})$ and hense flux or flux density (B).

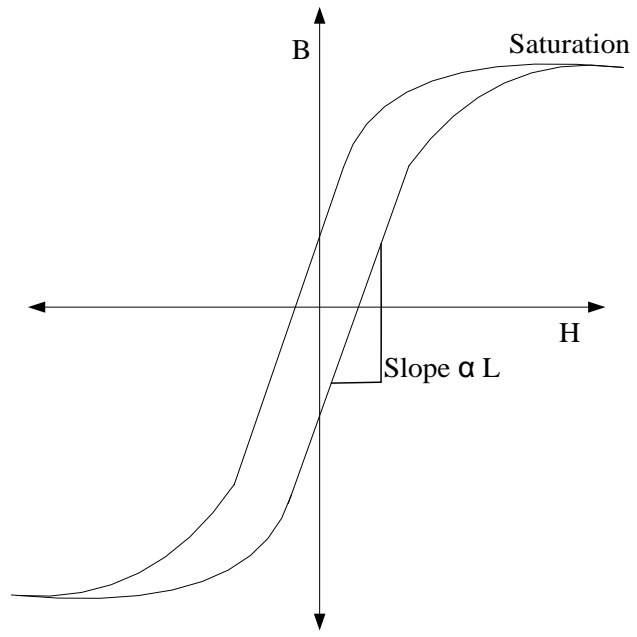

Fig.5B-H characteristics of inductor. 
Vol. 5, Issue 2, February 2017

The variations in $\mathrm{B}$ and $\mathrm{H}$ complete first quadrant of the B-H loop as shown in Fig.5. In this way it is different from the conventional line commutated topology.

In conventional topology current of almostconstant magnitude flows in inductor at dc side which set up constant magnitude of $\mathrm{H}$ in the core. At high value of $\mathrm{H}$, with constant magnitude, the slope on $\mathrm{B}-\mathrm{H}$ curve is small thus the effective value of inductance becomes small which is proportional to the slope on $\mathrm{B}-\mathrm{H}$ curve as shown in Fig.5. Therefore, inductor on dc side saturates and its effective value becomes low, thus to avoid saturation inductor of high rating is required which increases cost, size, weight and losses in the inductor.

However, in proposed topology partial reset or reversal of flux in B-H loop takes place due to half-wave dc current in the inductor, therefore the effectiveinductance is high, thus this topology does not requires inductor of high rating which reduces cost, size, weight and losses in the inductor.

\section{IV.COMPARISON OF SIMULATION RESULTS OF BOTH TOPOLOGIES}

A MATLAB/Simulink models of both, proposed and the conventional line commutated inverter have been developed to evaluate the performances of each converter and thus the result obtained from both topologies are compared.

Firing angle of thyristor is varied to obtain low harmonics (lower than 5\%) in line current with high amount of power injected into the grid.

In Simulation 230V (Grid voltage) is set at the primary of the transformer whose secondary winding is centre tapped, thus voltage on the secondary is also varied by changing the secondary winding turn ratios. In simulation different values of inductances are also used to understand its effect on the performance of the inverter.

\section{TABLE I SIMULATION PARAMETERS FOR BOTH TOPOLOGIES}

\begin{tabular}{|l|l|}
\hline Grid voltage & $230 \mathrm{~V}$ \\
\hline $\begin{array}{l}\text { Secondary side voltage } \\
\text { on treansformer }\end{array}$ & $220 \mathrm{~V}, 200 \mathrm{~V}, 150 \mathrm{~V}$ \\
\hline DC side inductance & $50 \mathrm{mH}, 70 \mathrm{mH}, 120 \mathrm{mH}$ \\
\hline Battery voltage (E) & $48 \mathrm{~V}$ \\
\hline
\end{tabular}

Below figures shows the comparison of THD in line current and power transferred into grid at different values of inductances for both topologies, i.e. Topology 1 (conventional) and Topology 2 (proposed) at various values of secondary side voltages.
A. For $220 \mathrm{~V}$ on secondary winding of transformer:

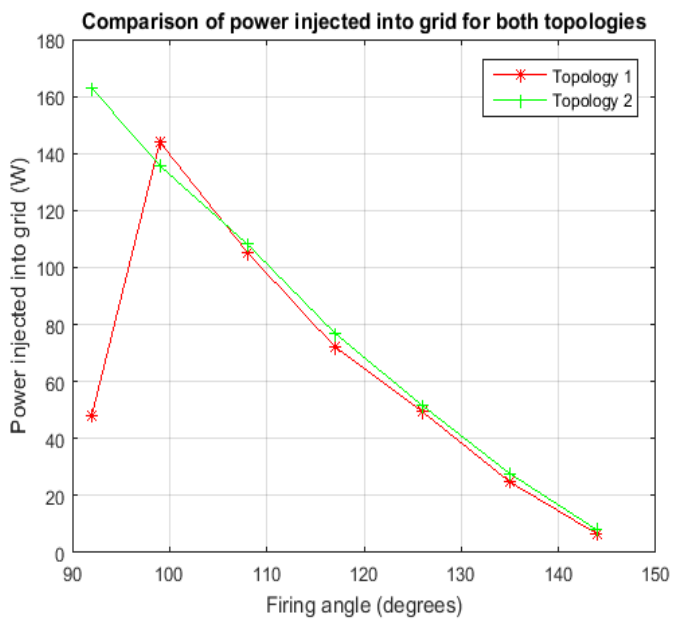

(a)

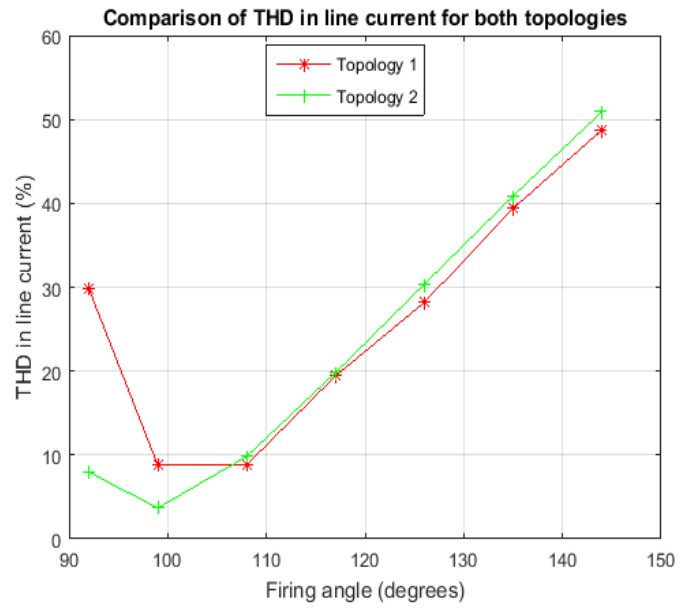

(b)

Fig.4For $\mathrm{L}=120 \mathrm{mH}$ on $\mathrm{DC}$ side

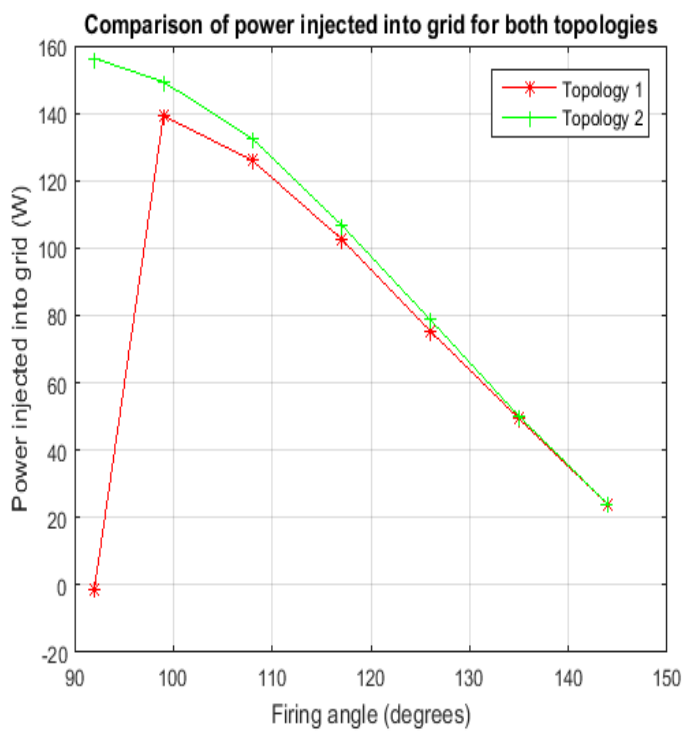

(a) 
International Journal of Innovative Research in Electrical, Electronics, Instrumentation and Control Engineering

ISO 3297:2007 Certified

Vol. 5, Issue 2, February 2017

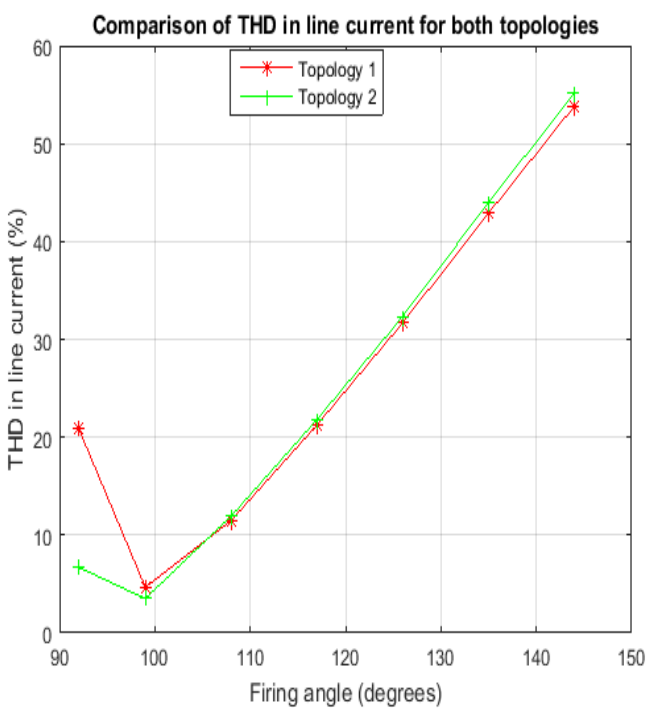

(b)

Fig.5For $\mathrm{L}=70 \mathrm{mH}$ on $\mathrm{DC}$ side

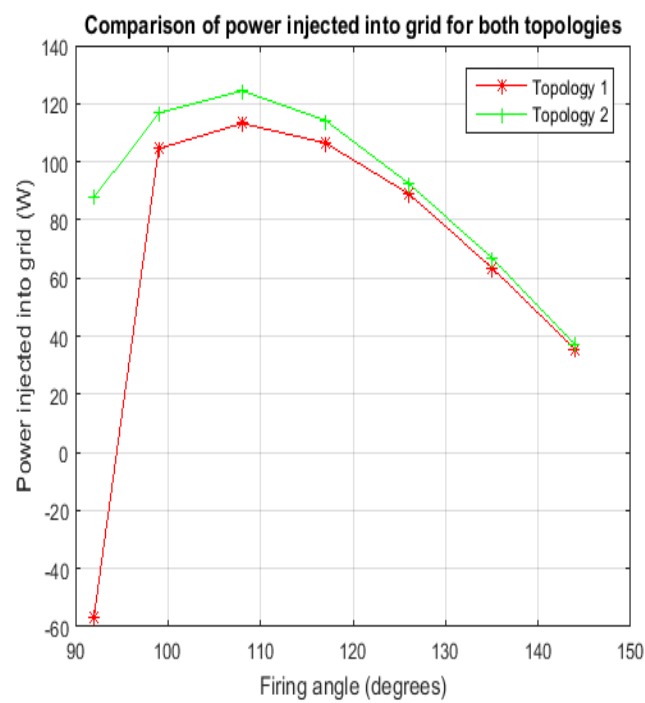

(a)

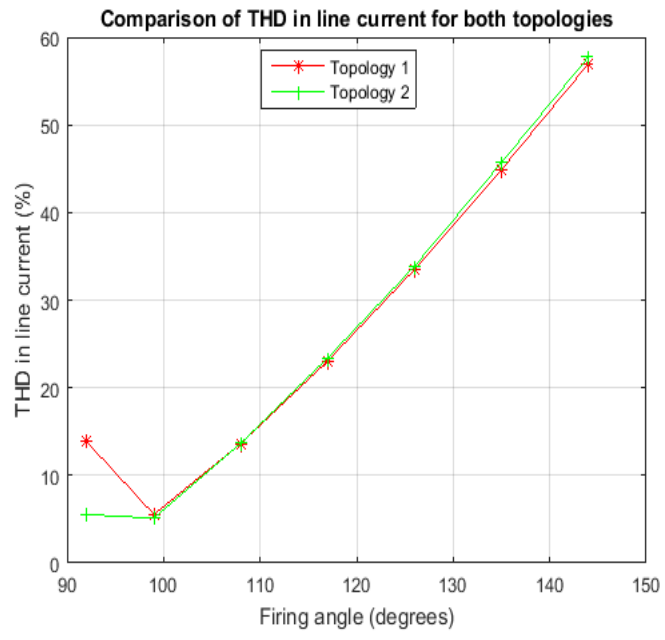

(b)

Fig.6For $\mathrm{L}=50 \mathrm{mH}$ on DC side
B. For $200 \mathrm{~V}$ on secondary winding of transformer:

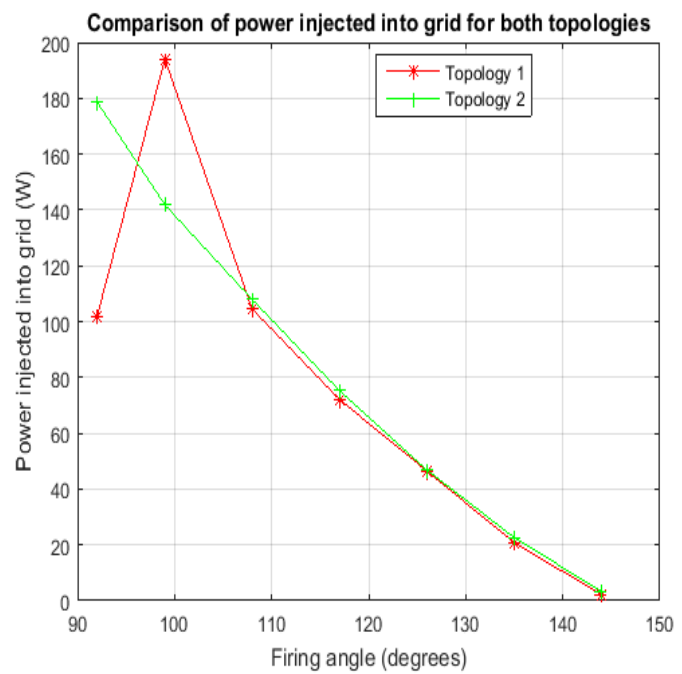

(a)

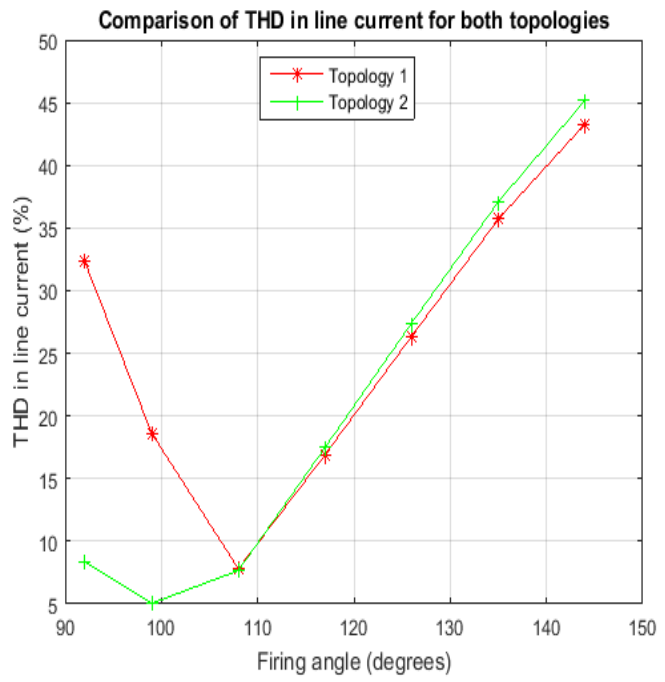

(b)

Fig.7For $\mathrm{L}=120 \mathrm{mH}$ on $\mathrm{DC}$ side

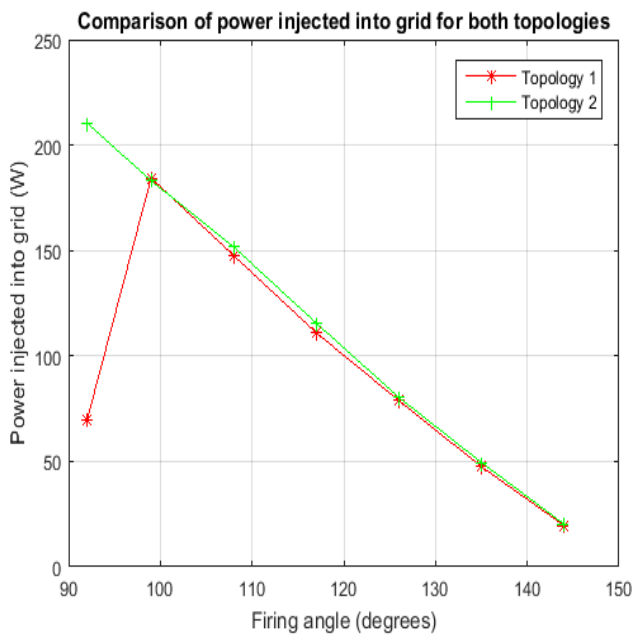

(a) 
International Journal of Innovative Research in Electrical, Electronics, Instrumentation and Control Engineering

ISO 3297:2007 Certified

Vol. 5, Issue 2, February 2017

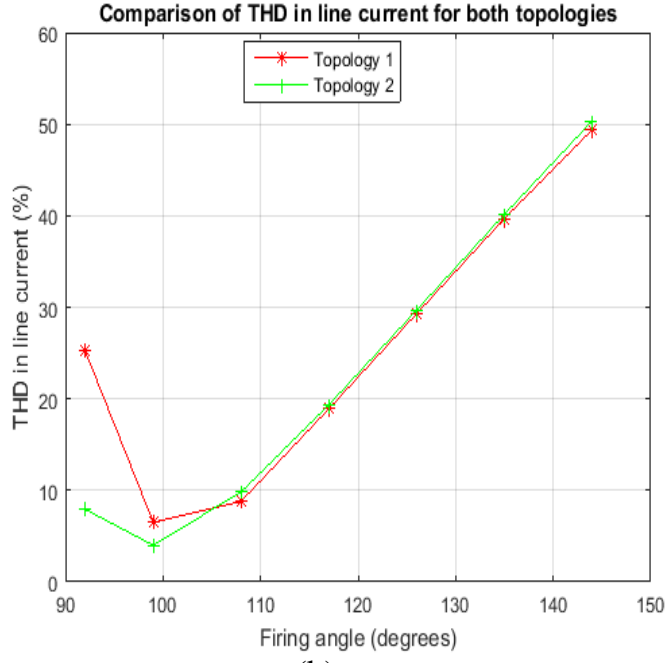

(b)

Fig.8For $\mathrm{L}=70 \mathrm{mH}$ on $\mathrm{DC}$ side

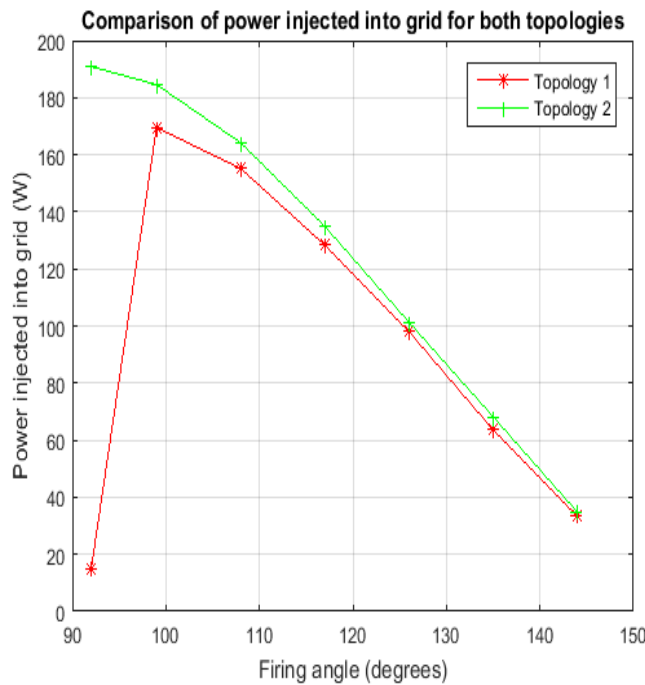

(a)

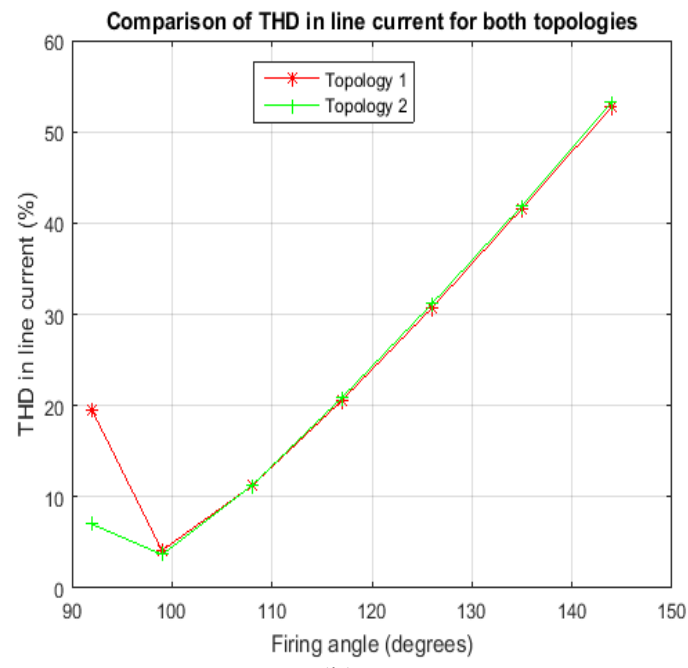

(b)

Fig.9For L=50 $\mathrm{mH}$ on DC side
C. For $150 \mathrm{~V}$ on secondary winding of transformer:

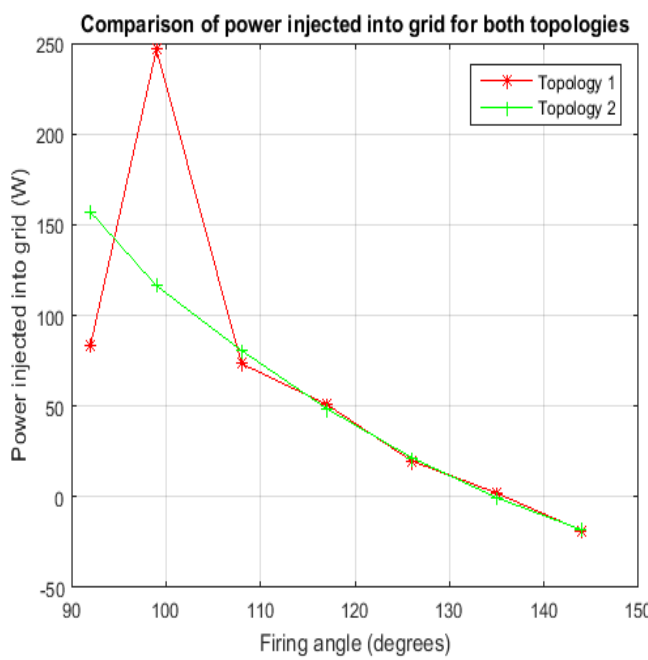

(a)

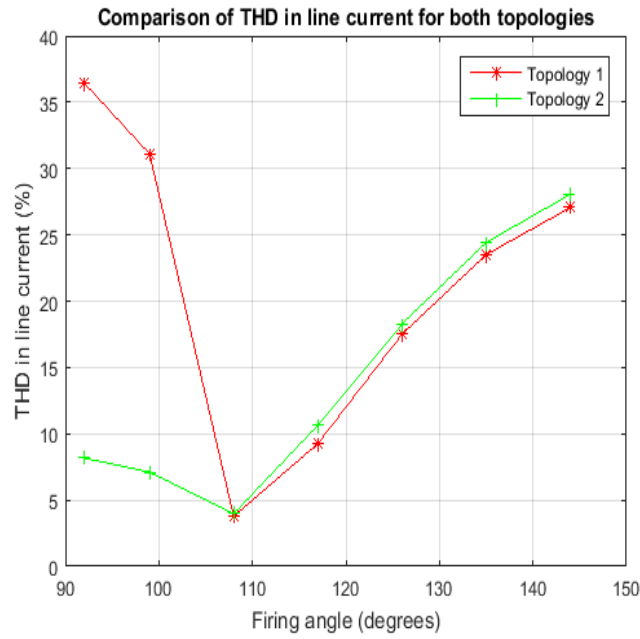

(b)

Fig.10For $\mathrm{L}=120 \mathrm{mH}$ on $\mathrm{DC}$ side

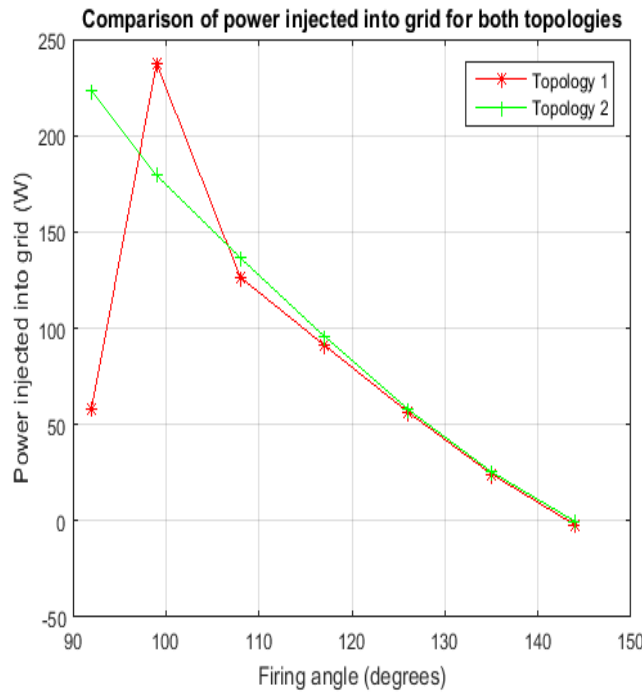

(a) 
Vol. 5, Issue 2, February 2017

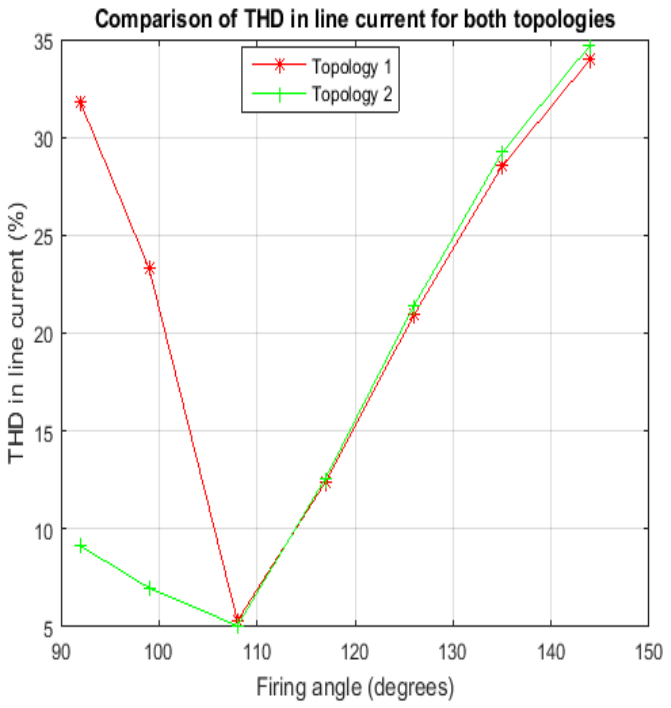

(b)

Fig.11For $\mathrm{L}=70 \mathrm{mH}$ on $\mathrm{DC}$ side

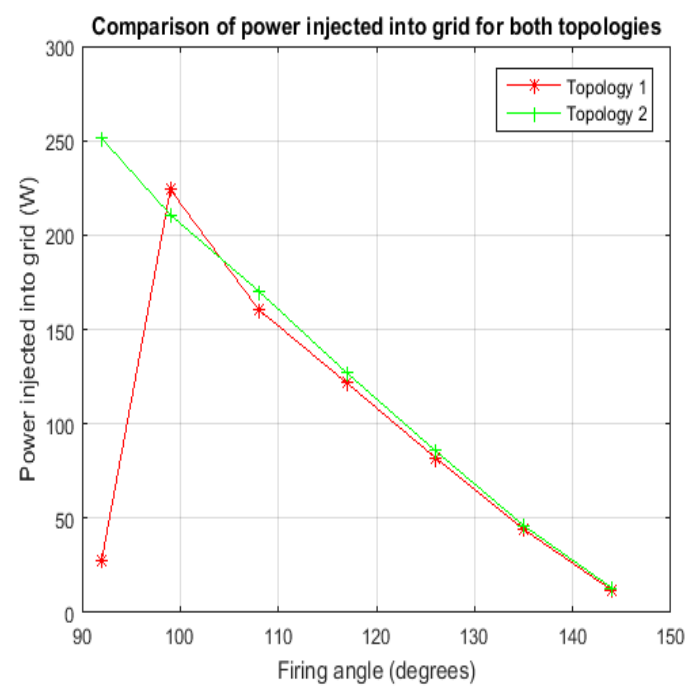

(a)

Fig.4 to Fig.12 shows detailed comparison of the simulation performances of both topologies.

It is inferred from above figures that topology 2 have lower amount of harmonics in line current and gives more power to grid for a particular value of inductance in comparison to topology 1 especially when firing angle is

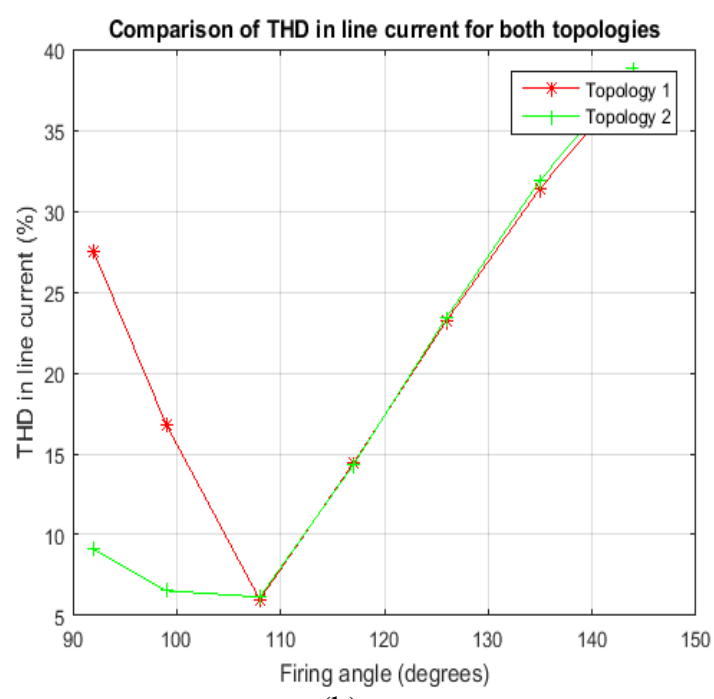

(b)

Fig.12For $\mathrm{L}=50 \mathrm{mH}$ on $\mathrm{DC}$ side

in between 90 degrees to110 degrees. Table II shows comparison between optimized conditions for both topologies, it gives clear representation that the topology 2 gives better results ie. minimum harmonics in line current with higher power fed to grid, with lower value of dc side inductance for a particular value of the voltage on secondary side of transformer.

Reduction in harmonics contents of line current in topology 2 in comparison to topology 1 is due to fact that the circuit on dc side acts as two independent circuits and thus it shapes the line current on ac side which is more close to sinusoidal shape.

Also there is a reduction in the size of inductance due to partial reversal of flux in B-H loop as the current in the dc side inductance goes to zero in each half cycle of the the ac voltage.

Thus with reduced harmonics in line current along with low power losses and low EMI as compared to conventional square wave inverter, proposed topologies is a better replacement for a grid-tied inverter system and it should be connected to grid with $150 \mathrm{~V}$ on secondary side of the transformer with $50 \mathrm{mH}$ inductance on dc side of inverter.

TABLE II OPTIMISED SIMULATION RESULTS

\begin{tabular}{|c|c|c|c|c|c|c|}
\hline \multirow{2}{*}{$\begin{array}{ll}\text { Voltage } & \text { on } \\
\text { secondary side } & \text { of } \\
\text { transformer }(\mathrm{V}) & \end{array}$} & \multicolumn{3}{|c|}{ Topology 1} & \multicolumn{3}{|c|}{ Topology 2} \\
\hline & THD (\%) & Power (W) & Induct-ancemH & THD (\%) & Power $(\mathrm{W})$ & Induct-ancemH \\
\hline 220 & 8.87 & 144.0 & 120 & 6.71 & 156.3 & 70 \\
\hline 200 & 18.61 & 194.0 & 120 & 7.94 & 210.0 & 70 \\
\hline 150 & 16.81 & 224.0 & 50 & 6.54 & 210.7 & 50 \\
\hline
\end{tabular}




\section{CONCLUSION}

A single phase, grid connected thyristor based converter is developed both in MATLAB/Simulink environment and the overall performances of both topologies are analysed and compared. It isobserved that for a low value of inductor on dc side proposed topology injects more power into grid with relatively low harmonics in line current, thus reduces the cost, size and weight of the converter. Thus it is optimized way to operate the proposed topology at the conditions given in last row of Table II.

\section{REFERENCES}

[1] Y. Xue, L. Chang, S. B. Kjær, J. Bordonau, and T. Shimizu, "Topologies of Single-Phase Inverters for Small Distributed Power Generators: An Overview," IEEE Trans. on Power Electron., vol. 19, no. 5, pp. 1350-1314, Sep. 2004

[2] S. V. Araújo, P. Zacharias, and R. Mallwitz, "Highly Efficient Single-Phase Transformerless Inverters for Grid-Connected Photovoltaic Systems," IEEE Trans. on Ind. Electron., vol. 57, no. 9, pp. 3118-3128, Sep. 2010.

[3] F.Edwin, W. Xiao, and V.Khadkikar, "Topology Review of Single Phase Grid-Connected Module Integrated Converters for PV Applications," in Proc.38th Annu. Conf. on IEEE Ind. Electron. Soc., 2012, pp. 821-827.

[4] W. -R.Liou, H. M. Villaruza, M. -L. Yeh, and P.Roblin, "A Digitally Controlled Low-EMI SPWM GenerationMethod for Inverter Applications,'IEEE Trans. on Ind.Informat., vol. 10, no. 1, pp. 73-83, Feb. 2014.

[5] Power Electronics Handbook,1st ed., Acad. Press, California, USA, 2001, pp. 169-182.

[6] A. Sarwar, and M. S. JamilAsghar, "Multilevel converter topology for solar PV based grid-tie inverters," in Proc. IEEE International Energy Conf. and Exhib., 2010, pp. 501-506.

[7] G. Zhu, X. Ruan, L. Zhang, and X. Wang, "On the Reduction of Second Harmonic Current andImprovement of Dynamic Response for Two-Stage Single-Phase Inverter,'IEEE Trans. on Power Electron., vol. 30, no. 2, pp. 1028-1041, Feb. 2015. 